of the Royal College of Psychiatrists has written that the bill represents "the worst of both worlds. The mentally ill will be subject to the power of 'arrest' and to no apparent purpose. Psychiatrists remain deeply sceptical and believe that the bill will not provide the extra public safety which the Government is hoping for." 11

At a recent meeting of the Parliamentary All Party Mental Health Group all professional, user, and other relevant bodies (except the National Schizophrenia Fellowship, representing carers) heavily criticised the bill. It is therefore opposed by nearly all the groups that will implement or be affected by aftercare under supervision.

The bill legally tinkers when what is needed is radical revision of the Mental Health Act 1983 designed to take account of the massive change in the provision of psychiatric services towards the community. ${ }^{12}$ It will fail in its stated purpose because it attempts to substitute legal rules for resources. It should be resisted and, if enacted, ignored. It removes civil rights without offering any appreciable clinical benefit and thus eschews any principle of reciprocity. ${ }^{12}$

Section of Forensic Psychiatry,

St George's Hospital Medical School,

London SW17 0RE

1 Department of Health. The ten point plan. London: DoH, 1993. (Press release H93/908.)

2 Ritchie J, Dick D, Lingham R. The report of the inquiry into the care and treatment of Christopher Clunis. London: HMSO, 1994

3 Department of Health. Introduction of supervision registers for mentally ill people. London: HMSO, 1994. (HSG (94)5.)

4 Wexler TJ. Essays in therapeutic jurisprudence. Durham, NC: Academic Press, 1991.

5 Thorold O. A mouse to tackle a mountain. Guardian $1995 \mathrm{Feb} 21$.

6 Blom-Cooper L, Hally H, Murphy E. The falling shadow. London: Duckworth, 1995.

7 Harrison K. Supervision in the community. New Law fournal 1994;144:1017.

8 Winterwerp v The Netherlands 19792 EHRR 387.

9 Department of Health. Legal powers on the care of mentally ill people in the community. Report of the internal review. London: $\mathrm{DoH}, 1993$.

10 Royal College of Psychiatrists. Community supervision orders. London: RCP, 1993.

11 Thompson C. New powers for care of mentally ill. Times 1995 Mar 23:17.

12 Eastman N. Mental health law: civil liberties and the principle of reciprocity. BMF 1994;308:43-5.

\title{
Cigarettes and addiction
}

\section{Regulation of tobacco products is inconsistent with their effects on health}

Unless the prevalence of smoking falls substantially, 0.5 billion of the world's present population will die prematurely from disease caused by tobacco. ${ }^{1}$ Without considerable changes in the regulation of products that deliver nicotine it will be difficult to achieve substantial further falls in mortality in the United States or to reduce tobacco consumption worldwide. Under the direction of its commissioner, David Kessler, the United States Food and Drug Administration is taking on this challenge. The federal agency is considering taking over regulatory responsibility for tobacco products and developing new regulatory approaches for tobacco. What has brought about its involvement, and what can it do? We provide some insight into these issues from the perspective of public health scientists who do not represent the Food and Drug Administration or other federal agencies.

Tobacco products are not regulated in a way that is consistent with their adverse effects on health and their addictiveness. ${ }^{2}$ Ironically, in the United States the present system of regulatory oversight of products that deliver nicotine makes it easier to get tobacco products, which cause dependence and disease, than to obtain potentially lifesaving drugs. Thus the most toxic and addictive formulations delivering nicotine - cigarettes and other tobacco productsare readily available over the counter and from vending machines; they are not regulated by the federal agency responsible for the safety of food and drugs. In contrast, the medicinal formulations that deliver nicotine (gums and patches), which are far safer and much less addictive than tobacco products, are available only with a prescription, are sold only through pharmacies, are officially approved for only a few months of administration, and are regulated by the Food and Drug Administration.

Another deficiency of the United States's present regulatory approach is that meaningful information about the nicotine dose of cigarettes is not provided to consumers, and no dosing information is provided regarding chewing tobacco, snuff, cigars, or pipe tobacco. The information provided for cigarettes is at best misleading and at worst seems to benefit the tobacco industry in its marketing efforts. For example, estimates of nicotine and tar delivery derived from smoking machines enable tobacco companies to imply that cigarettes delivering "full flavour" with "reduced tar and nicotine" have health advantages, and these cigarettes now make up most of the American cigarette market. ${ }^{3}$ Much research has shown that so called low yield cigarettes can deliver as much tar and nicotine as higher yield cigarettes. In the United States, estimates of the doses from cigarettes are provided to the public by the Federal Trade Commission (which generally oversees advertising claims of products other than drugs) and not by the Food and Drug Administration, which has extensive experience in assessing the bioavailability of drugs. Presumably, developing strategies to regulate doses would be straightforward for the Food and Drug Administration.

In 1988 the Coalition on Smoking or Health petitioned the Food and Drug Administration to regulate the manufacture, sale, distribution, labelling, advertising, and promotion of cigarettes and other tobacco products. Three main factors were cited in support of the petition: that use of tobacco products results in nicotine addiction; that tobacco companies have developed and marketed their products as drug delivery systems, knowing that that is how consumers use them; and that the increasing diversity of systems that deliver nicotine being developed by tobacco companies requires the oversight of the Food and Drug Administration.

The agency took little action to resolve these issues until 1992, when its newly appointed commissioner ordered a systematic review of the merits of the petition. By 1994 Kessler had concluded that the petition had sufficient merit to warrant a full investigation. Additional pressure to move forward was provided by the findings of an American television investigative news programme (ABC, Day 1) in February 1994, which concluded that tobacco companies explicitly manipulate the nicotine content of tobacco products to facilitate the development and maintenance of nicotine addiction.

The Food and Drug Administration testified before the US Congress on 25 March and 21 June last year, providing further evidence of the extent to which the tobacco industry was engaged in research and manufacturing strategies similar to those of pharmaceutical companies. ${ }^{4}$ Moreover, the Food and Drug Administration's investigation showed that the tobacco industry understood that long term use of tobacco 
was maintained primarily by the pharmacological effects of nicotine. An advisory panel to the Food and Drug Administration subsequently concluded that nicotine was addictive and that all cigarettes available in the United States can provide addicting levels of nicotine.

Recent biomedical research on the nature and mechanisms of nicotine addiction supports the consideration of regulatory reform. For example, nicotine has certain effects and mechanisms in common with cocaine, including the involvement of dopaminergic transmitters. Research is unravelling the specific mechanisms by which nicotine influences behaviour. ${ }^{5}$ Exposure to nicotine produces lasting changes in the body's structure, which include increased expression and reduced turnover of nicotine receptors in the brain; these seem to be important in the development of tolerance and dependence. ${ }^{6-8}$ Nicotine also has potentially beneficial effects on performance, which are reportedly sought by many tobacco users and could facilitate the development and maintenance of addiction. ${ }^{910}$

Possible strategies to be overseen by the Food and Drug Administration could include new systems of evaluating cigarettes' dosing characteristics, ${ }^{3}$ restrictions on the amount of nicotine in tobacco products, ${ }^{11}$ and new restrictions on advertising and marketing. ${ }^{2}$ Prohibition is unlikely. The Food and Drug Administration is clearly committed to examining the range of options available and developing solutions with the long term potential of substantially reducing tobacco use and death and disease caused by tobacco. ${ }^{4}$ The clock may be slowed by any number of events, but to turn it back will be difficult given the extensive findings that commercial tobacco products are systems that deliver an addictive drug and confer a high risk of disability and death.
The views expressed in this paper are those of the authors and do not reflect an official position of the US federal government or its agencies.

JACK E HENNINGFIELD

Chief

Clinical Pharmacology Branch,

NIDA Addiction Research Center,

PO Box 5180,

Baltimore, MD 21224,

USA

Division of Clinical Pharmacology and

Experimental Therapeutics,

University of California,

San Francisco, CA 94941,

USA

1 Peto R, Lopez AD, Boreham J, Thun M, Heath C Jr. Mortality from smoking in developed countries 1950-2000. Oxford: Oxford University Press, 1994

2 Ballin SD. Statement of Scott D Bailin. Hearing before the subcommittee on health and the environment, fuly 29, 1988. Washington, DC: US Government Printing Office, 1988:122-32. (Serial No 100-68.)

3 Henningfield JE, Kozlowski LT, Benowitz NL. A proposal to develop meaningful labelling for cigarettes. ЭAMA 1994;272:312-4.

4 Kessler DA. Statement on nicotine-containing cigarettes. Tobacco Control 1994;3:148-58.

5 Corrigall WA, Coen KM, Adamson KL. Self-administered nicotine activates the mesolimbic dopamine system through the ventral tegmental area. Brain Res 1994;653:278-84.

6 Collins AC, Robinson SF, Marks M. Individual differences in tobacco use may be related to genetically-determined differences in responses to nicotine. In: Clarke PBS, Quik M, Adlkofer FX, Thurau K, eds. The effects of nicotine on biological systems II. Basle: Birkhauser Verlag (in FX, Thur
press).

7 Davila-Garcia MI, Xiao Y, Houghtling RA, Oasba SS, Fiores CM, Kellar KJ. Regulation of neuronal nicotinic receptors in primary culture. In: Clarke PBS, Quik M, Adlkofer FX, Thurau $\mathrm{K}$, eds. The effects of nicotine on biological systems II. Basle: Birkhauser Verlag (in press).

8 Peng X, Gerzanich V, Anand R, Whiting PJ, Lindstrom J. Nicotine-induced increase in neuronal nicotinic receptors results from a decrease in the rate of receptor turnover. Mol Pharmacol 1994;46:523-30.

9 Heishman SJ, Taylor RC, Henningfield JE. Nicotine and smoking: a review of effects on human performance. Experimental and Clinical Psychopharmacology 1994;2:1-51.

10 Henningfield JE. Comments on West's editorial "Beneficial effects of nicotine: fact or fiction?" Addiction 1994;89:135-46.

11 Benowitz NL, Henningfield JE. Establishing a nicotine threshold for addiction. $N$ Engl $\mathcal{F}$ Med 1994;331:123-4.

\section{Health checks in general practice}

\section{Time to review their role}

The NHS has changed a lot since the late Denis Burkitt (who linked high fibre diets with preventing bowel disease) compared illness to an overflowing bath and suggested that doctors and nurses might be better employed turning off taps than mopping the floor. Increasingly, general practice has been considered to be the right place for turning off taps, ${ }^{12}$ and in 1990 health promotion was made a contractual requirement for general practitioners. ${ }^{3}$ Does prevention of illness in primary care work? Three papers in this week's journal consider different aspects of that question. ${ }^{4-6} \mathrm{Un}$ surprisingly, the answer is not straightforward.

One group based in Oxford, testing strategies to reduce the risks of cardiovascular disease and cancer in general practice populations, has greatly influenced British health policy. It is to the OXCHECK researchers' credit, therefore, that evangelistic fervour has not clouded their evaluative judgment. In their latest report they conclude that health checks for unselected middle aged people achieve little or no reduction in smoking and excessive drinking (p 1099). ${ }^{4}$ The most encouraging results were change in lifestyle-better diets, increased exercise-and falls in serum cholesterol concentrations. These changes were sustained over three years.

Crucial issues in health promotion are knowing how best to intervene and whom to target. Lindholm and colleagues, reporting from Sweden on middle aged people with at least two cardiovascular risk factors, found intensive group education about the risks of cardiovascular disease to be more effective than standard advice in reducing total serum cholesterol concentrations ( $p$ 1105). ${ }^{5}$ The differences, however, are small, and many trends do not reach significance. This underlines the need to enrol large numbers of patients if such studies are to give unequivocal results.

Perhaps most interesting for British general practice is Field and colleagues' modelling of the cost effectiveness of different strategies (p 1109), ${ }^{6}$ using data from the OXCHECK trial. ${ }^{4}$ They predict that the most cost effective way to reduce the risk of coronary heart disease in general practice populations would be to target high risk groups.

One must beware of reading too much into these results. The cost effectiveness study had to make several assumptions, not necessarily all valid. In addition, the success of skilled procedures often varies considerably among operators. This may be as true for the interpersonal skills used in promoting behavioural change as for manual skills in surgery. Reluctant practices doing checks solely to receive payments for health promotion or to fulfil their terms of service may do far worse than the highly motivated and specially trained practices in Bedford that took part in the OXCHECK study. Populations also vary considerably. Prevention is a low priority in some groups, often for very good reasons. ${ }^{7}$ Generalising from Sweden to Britain, or even from Bedford to Hackney, may not be possible.

Despite these caveats the papers have some important 